\title{
Comparison of ultrasound and positive contrast arthrography in the diagnosis of popliteal and calf swellings
}

\author{
H. B. MEIRE, D. J. LINDSAY, D. R. SWINSON, AND E. B. D. HAMILTON \\ From the Departments of Physical Medicine and Diagnostic Radiology, King's College Hospital, London
}

Popliteal cysts have for long been recognized as a not uncommon accompaniment of chronic arthritis of the knee joint (Adams, 1840; Baker, 1877), and in recent years there have been frequent reports of their occurrence in patients with rheumatoid arthritis (Meyerding and Van Demark, 1943; Harvey and Corcos, 1960; Maudsley and Arden, 1961; and Hall and Scott, 1966). Detailed pressure studies by Jayson and Dixon (1970) have supported the view that a valvular mechanism is responsible for their formation and persistence, and it has been claimed that they may protect the knee joint from excessive damage (Genovese, Jayson, and Dixon, 1972). Attempts at removal of these cysts frequently lead to their recurrence, or to fistula formation (Bennett, Hughes, Bywaters, and Holt, 1972), so that anterior synovectomy may be the treatment of choice for large cysts which are causing symptoms (Jayson, Dixon, Kates, Pinder, and Coomes, 1972). A recognized complication of such cysts is rupture into the calf simulating a deep vein thrombosis (Tait, Bach, and Dixon, 1965; Myles, 1971).

Genovese and others (1972), in 36 rheumatoid knees, found that only four out of ten popliteal cysts could be detected on clinical examination, but it is well known that such cysts can readily be shown by arthrography. Arthrography of the knee is generally a safe examination, but does involve the patient in some discomfort and there is a possibility that infection may be introduced. We have therefore been investigating the possibility of using an ultrasound scanning machine to produce an image of the posterior aspect of the knee and calf.

\section{Material and methods}

The machine used is an Aloka SSD 10 which has both ' $A$ ' and ' $B$ ' scan presentation and is normally used for examining pregnancies and abdominal space-occupying lesions. Examination with the ultrasound machine involves holding a small transducer in contact with the skin and moving it over the area under investigation. Very brief pulses of sound are passed into the tissues and the echoes returning to the surface are displayed on a cathode ray screen either as a ' $B$ ' scan to produce a sectional image (Fig. 1a), or as an 'A' scan for the purpose of measurement of internal dimensions and tissue density (Fig. $1 d$ and $2 b$ ). (For further information on ultrasound imaging see Talbert and Campbell, 1972).

The technique is quick, painless, non-invasive, and, so far as can be shown to date, harmless. Any information obtained is therefore gained at little cost in time, money, distress, or hazard.

Patients in this study had either calf swelling or popliteal pain with or without a palpable cyst. Scanning was carried out with the patient lying comfortably in the prone position, longitudinal scans being taken at $1 \mathrm{~cm}$. intervals across the popliteal space and calf.

Arthrography was done via the retro-patellar route under local anaesthesia and using up to $20 \mathrm{ml}$. Conray 280 , films being obtained both before and after injection and after exercise.

\section{Results}

Twenty patients have been examined by both ultrasound and positive contrast arthrography. Eighteen had rheumatoid involvement of the knee, one had calf and popliteal pain after menisectomy, and one had a swollen calf as a result of a road accident. Four of the patients with rheumatoid arthritis had both knees examined. The correlation of the results of both techniques is shown in the Table (p. 224). In 22 out of the 24 knees, there was good correlation for the presence of cysts. A false negative scan was obtained in Case 20, in which a small cyst was shown at arthrography to have ruptured and emptied, and in Case 19 the clinical impression of a cyst was confirmed by ultrasound but not by arthrography-presumably because the cyst was no longer in free communication with the knee joint space.

One patient (Case 13) had a cyst demonstrated by ultrasound which was not detected clinically, and in three patients (Cases $1,4,7$ ) the clinical impression 


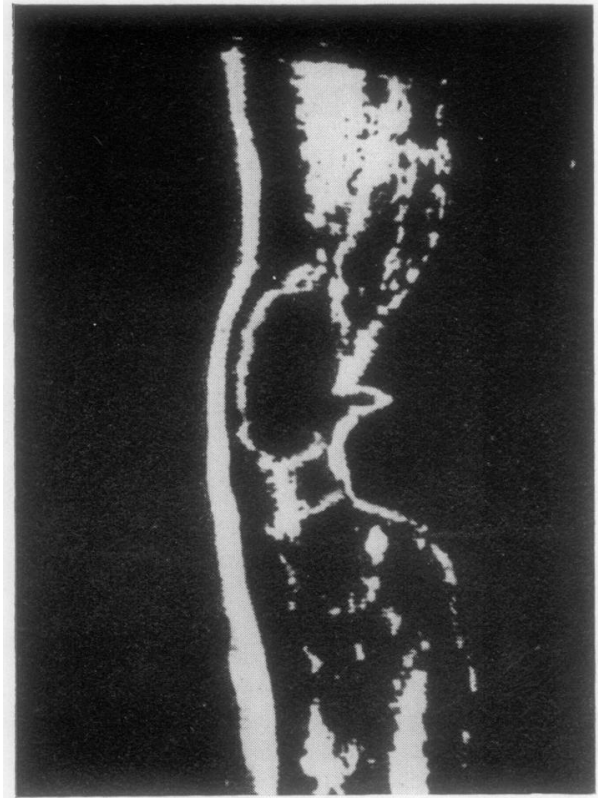

(a)

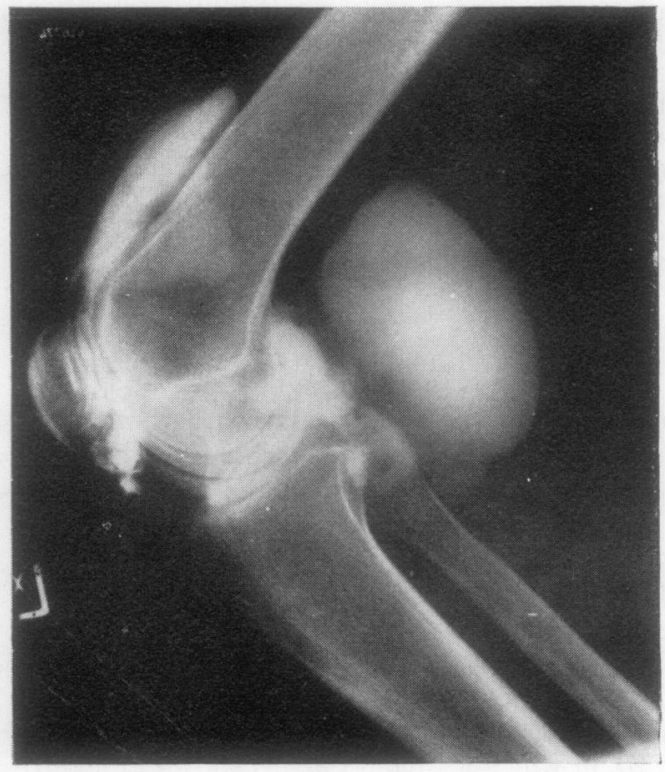

(c)

of a cyst was not confirmed by ultrasound or arthrography. Cases 3, 8, and 19 had unsuspected superior extensions of the cysts detected by ultrasound and in Cases 3 and 8 this finding was confirmed by arthrography.

Three other patients (Cases 21, 22, and 23), who had popliteal or calf pain, were examined by ultrasound only, since the ultrasound diagnoses were clear and arthrography not felt to be indicated.
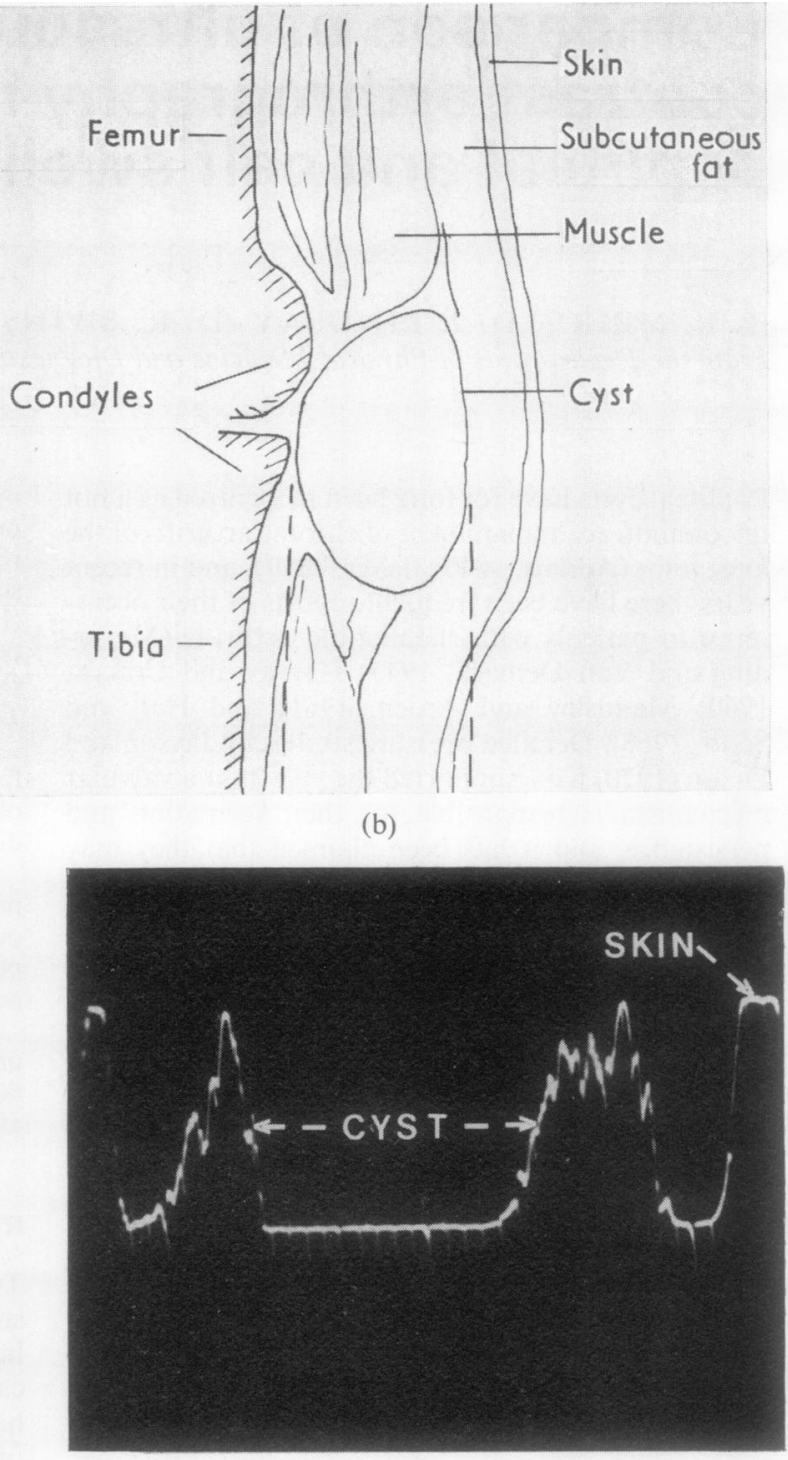

(d)

FIG. 1 (a) Ultrasound ' $B$ ' scan of popliteal cyst. (b) Line diagram of $(a)$. (c) Positive contrast arthrogram of same knee. (d) ' $A$ ' scan over cyst, showing diameter $(3 \mathrm{~cm}$.) and 'clear' contents

In those cases in which cysts have been detected by ultrasound it has been possible to measure the maximum diameter of the cyst using the ' $A$ ' scan and also to assess the quantity of inspissated debris within the cyst (Fig. 2). The results of these estimations have correlated well with the arthrographic findings. The left-sided popliteal cyst of Case 2 was shown to have a maximum diameter of $3.2 \mathrm{~cm}$. on ultrasound ' $A$ ' scan and measured $3.4 \mathrm{~cm}$. on the arthrogram. The 


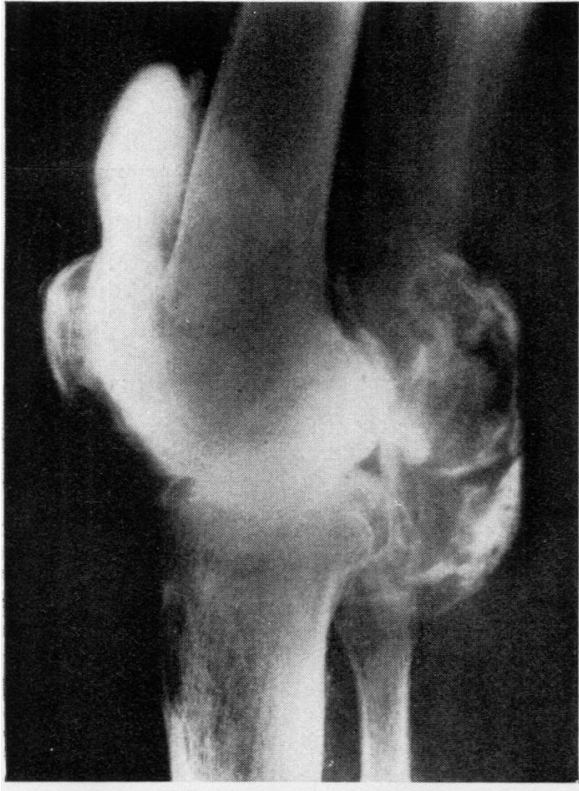

(a)

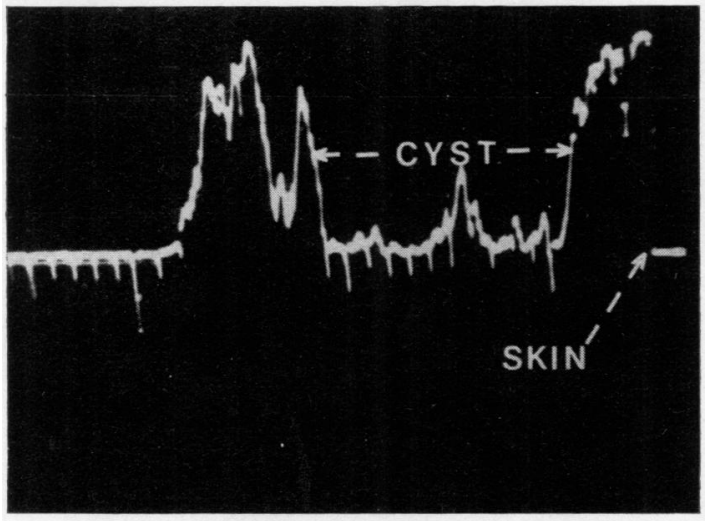

(b)

FIG. 2 (a) Arthrogram of knee containing debris within the cyst. (b) ' $A$ ' scan through cyst. Note that the debris within the cyst has produced small echoes in the otherwise 'clear' area

right knee cyst of Case 3 was $4.3 \mathrm{~cm}$. on ultrasound and $4.6 \mathrm{~cm}$. by $x$ ray measurement. In no case was there more than $0.5 \mathrm{~cm}$. disparity between the ultrasound and $x$ ray measurements, the latter being usually 3 or $4 \mathrm{~mm}$. larger than the ultrasound figures. This may be attributable to the slight magnification inherent in all radiographic techniques.

\section{Discussion}

Facilities for ultrasound scanning are becoming increasingly available and the technique is an accepted method of visualizing internal structures (Wells, 1972). McDonald and Leopold (1972) described its use in the diagnosis of large calf cysts in four patients and found it useful in differentiating calf cysts from other causes of calf swelling.

This survey has confirmed their findings and demonstrated that quite small and clinically undetectable cysts can be shown by ultrasound scanning and that their diameters can be accurately measured. Our only false negative result was in a patient whose small cyst had probably emptied and we had no false positives.

The limitations of the technique are that it will not reliably detect cysts of much less than $2 \mathrm{~cm}$. diameter and that, if the cyst were filled with a large quantity of inspissated debris, it might not be readily visualized or might be interpreted as a solid mass. We have not had such a case.

Ultrasound has some advantages over arthrography since it does not rely on a persistent communication between the joint space and the cyst and is quick, painless, and safe.

We would suggest, therefore, that ultrasound scanning, when available, offers a useful means of screening patients suspected of having calf cysts and that in some cases positive contrast arthrography might be avoided. It is also an excellent means of assessing the progress of these lesions and of measuring the response of the cyst to treatment.

\section{Summary}

Ultrasound imaging of the popliteal fossa and calf is described and compared with positive contrast arthrography in 24 knees. The techniques agreed for the presence of cysts in 22 out of the 24 knees. Ultrasound did not detect a small cyst that had leaked but did detect a cyst which did not fill on retropatellar arthrography. Measurements of the size of the cysts on arthrography and ultrasound also show close agreement.

Ultrasound is a safe and reliable technique for detecting and assessing popliteal cysts. Its chief advantages are lack of pain and non-invasiveness, and its disadvantage is that it may not detect a cyst which is leaking.

\section{References}

Adams, R. (1840) Dublin J. med. Sci., 17, 520 (Chronic rheumatoid arthritis of the knee joint)

BAKER, W. M. (1877) St. Bart's Hosp. Rep., 13, 245 (Formation of synovial cysts in the leg in connection with disease of the knee joint) 
Table Particulars of 23 examinations

\begin{tabular}{|c|c|c|c|c|c|c|c|}
\hline \multirow[t]{2}{*}{ Case no. } & \multirow[t]{2}{*}{ Diagnosis } & \multirow{2}{*}{$\begin{array}{l}\text { Clinical } \\
\text { impression }\end{array}$} & \multirow[t]{2}{*}{ Side } & \multicolumn{2}{|l|}{ Diagnosis } & \multirow[t]{2}{*}{ Venogram } & \multirow[t]{2}{*}{ Correlation } \\
\hline & & & & Ultrasound & Arthrogram & & \\
\hline 1 & $\begin{array}{l}\text { Post- } \\
\text { menisectomy }\end{array}$ & CS & - R & NAD & NAD & - ve $\times 3$ & + \\
\hline 2 & RA & PC & $\left\{\begin{array}{l}\mathbf{R} \\
\mathbf{L}\end{array}\right.$ & $\begin{array}{l}\text { CD } \\
\text { CD }\end{array}$ & $\begin{array}{l}\mathrm{CD} \\
\mathrm{CD}\end{array}$ & & $\stackrel{+}{+}$ \\
\hline $\begin{array}{l}3 \\
4 \\
5\end{array}$ & $\begin{array}{l}\text { RA } \\
\text { T } \\
\text { RA }\end{array}$ & $\begin{array}{l}\text { PC } \\
\text { CC } \\
\text { PC }\end{array}$ & $\begin{array}{l}\mathbf{R} \\
\mathbf{L} \\
\mathbf{R}\end{array}$ & $\begin{array}{l}\text { CD } \\
\text { NAD } \\
\text { CD }\end{array}$ & $\begin{array}{l}\text { CD } \\
\text { NAD } \\
\text { CD }\end{array}$ & $-\mathrm{ve} \times 2$ & $\begin{array}{l}+ \\
+ \\
+\end{array}$ \\
\hline 6 & RA & PC & $\left\{\begin{array}{l}\mathbf{R} \\
\mathbf{L}\end{array}\right.$ & $\begin{array}{l}\text { CD } \\
\text { CD }\end{array}$ & $\begin{array}{l}\text { CD } \\
\text { CD }\end{array}$ & & $\begin{array}{l}+ \\
+\end{array}$ \\
\hline $\begin{array}{l}7 \\
8\end{array}$ & $\begin{array}{l}\text { RA } \\
\text { RA }\end{array}$ & $\begin{array}{l}\text { PC } \\
\text { PC }\end{array}$ & R & & $\begin{array}{l}\text { NAD } \\
\text { CD }\end{array}$ & & + \\
\hline 9 & RA & PC & $\left\{\begin{array}{l}R \\
L\end{array}\right.$ & $\begin{array}{l}\text { CD } \\
\text { CD }\end{array}$ & $\begin{array}{l}\text { CD } \\
\text { CD }\end{array}$ & & + \\
\hline $\begin{array}{l}10 \\
11\end{array}$ & $\begin{array}{l}\text { RA } \\
\text { RA }\end{array}$ & $\begin{array}{l}\text { PC } \\
\text { PC }\end{array}$ & $\mathrm{R}$ & CD & CD & & + \\
\hline 12 & RA & PC & $\left\{\begin{array}{l}\mathrm{L} \\
\mathbf{R}\end{array}\right.$ & $\begin{array}{l}\mathrm{C} \\
\mathrm{C}\end{array}$ & $\begin{array}{l}\text { CD } \\
\text { CD }\end{array}$ & & $\begin{array}{l}+ \\
+\end{array}$ \\
\hline $\begin{array}{l}13 \\
14 \\
15 \\
16 \\
17 \\
18 \\
19 \\
20\end{array}$ & $\begin{array}{l}\text { RA } \\
\text { RA } \\
\text { RA } \\
\text { RA } \\
\text { RA } \\
\text { RA } \\
\text { RA } \\
\text { RA }\end{array}$ & $\begin{array}{l}\text { ?PC } \\
\text { PC } \\
\text { PC } \\
\text { PC } \\
\text { CC } \\
\text { PC } \\
\text { PC } \\
\text { ?PC }\end{array}$ & $\begin{array}{l}\mathbf{R} \\
\mathbf{L} \\
\mathbf{R} \\
\mathbf{R} \\
\mathbf{R} \\
\mathbf{R} \\
\mathbf{R} \\
\mathbf{L}\end{array}$ & $\begin{array}{l}\text { C } \\
C \\
C \\
C D \\
C \\
C \\
\text { CD } \\
\text { CD } \\
\text { NAD }\end{array}$ & $\begin{array}{l}\text { C } \\
\text { C } \\
\text { C } \\
\text { CD } \\
\text { C } \\
\text { CD } \\
\text { NAD } \\
\text { CDL }\end{array}$ & & $\begin{array}{l}+ \\
+ \\
+ \\
+ \\
+ \\
+ \\
-\end{array}$ \\
\hline $\begin{array}{l}21 \\
22 \\
23\end{array}$ & $\begin{array}{l}\text { RA } \\
\text { RA } \\
\text { T }\end{array}$ & $\begin{array}{l}\text { ?PC } \\
\text { PC } \\
\text { CS }\end{array}$ & $\begin{array}{l}\mathbf{L} \\
\mathbf{R} \\
\mathbf{L}\end{array}$ & $\begin{array}{l}\text { NAD } \\
\text { CD } \\
\text { C }\end{array}$ & & $-\mathrm{ve} \times 1$ & \\
\hline
\end{tabular}

T-Trauma.

CS-Calf swelling.

RA-Rheumatoid arthritis.

PC-Capliteal cysts.

C-Cyst with no debris
CD-Cyst with debris.

L-Leaking.

Bennett, R. M., Hughes, G. R. V., Bywaters, E. G. L., And Holt, P. J. L. (1972) Ann. rheum. Dis., 31, 482 (Studies of a popliteal synovial fistula)

Genovese, G. R., JAYson, M. I. V., AND Dixon, A. ST. J. (1972) Ibid., 31, 179 (Protective value of synovial cysts in rheumatoid knees)

Hall, A. P., AND SCOTT, J. T. (1966) Ibid., 25, 32 (Synovial cysts and rupture of the knee joint in rheumatoid arthritis. An arthrographic study)

HARVEY, J. P., AND CORCOS, J. (1960) Arthr. and Rheum., 3, 218 (Large cysts in lower leg originating in the knee occurring in patients with rheumatoid arthritis)

Jayson, M. I. V., AND Dixon, A. St. J. (1970) Ann. rheum. Dis., 29, 415 (Valvular mechanisms in juxta-articular cysts)

,-- , Kates, A , Pinder, I., AND Coomes, E. N. (1972) Ibid., 31, 9 (Popliteal and calf cysts in rheumatoid arthritis)

MaUdSLEY, R. H., AND ARDEN, G. P. (1961) J. Bone Jt Surg., 43B, 87 (Rheumatoid cysts of the calf and their relation to Baker's cyst of the knee)

MCDonAlD, D. G., AND LeOPOLD, G. R. (1972) Brit. J. Radiol., 45, 729 (Ultrasound B scanning in the differentiation of Baker's cysts and thrombophlebitis)

Meyerding, H. W., AND VanDemark, R. E. (1943) J. Amer. med. Ass., 122, 858 (Posterior hernia of the knee)

Myles, A. B. (1971) Proc. roy. Soc. Med., 64, 262 (Posterior synovial leaks in arthritis of the knee)

TAIT, G. B. W., BACH, F., AND Dixon, A. ST. J. (1965) And. rheum. Dis., 24, 273 (Acute synovial rupture. Further observations)

TAlbert, D. G., AND Campbell, S. (1972) Brit. J. Hosp. Med., 8, 501 (Physical aspects of diagnostic ultrasound)

WeLLS, P. N. T. (ed.) (1972) 'Ultrasonics in Clinical Diagnosis'. Churchill, Livingstone, London 